\title{
EFFECT OF CASTING CONDITIONS AND HEAT TREATMENT ON HIGH TEMPERATURE LOW CYCLE FATIGUE PERFORMANCE OF NICKEL SUPERALLOY INCONEL 713LC
}

\author{
Ivo ŠULÁK, Karel OBRTLÍK, Karel HRBÁČEK \\ ${ }^{1}$ Institute of Physics of Materials, Academy of Sciences of the Czech Republic, Brno, Czech Republic, EU, \\ sulak@ipm.cz,obrtlik@ipm.cz, hrbacekl@ipm.cz
}

https://doi.org/10.37904/metal.2019.752

\begin{abstract}
The present work is focused on the study of high temperature low cycle fatigue behaviour of Inconel 713LC produced by a vibratory investment casting (VIC) in as-cast conditions and in the condition after heat treatment (HT) consisting of hot isostatic pressing (HIP) followed by precipitation hardening. Low cycle fatigue tests were carried out on cylindrical specimens in symmetrical push-pull cycle under strain control with constant total strain amplitude and strain rate at $800{ }^{\circ} \mathrm{C}$ in air. Hardening/softening curves and fatigue life curves of both materials were assessed and compared with data of Inconel 713LC produced by a conventional investment casting $(\mathrm{CIC})$. Cyclic hardening can be observed in the high amplitude domain while saturated stress response is apparent for low amplitude cycling for all material batches. Data presented in Basquin representation show an increase in fatigue life of both VIC batches compared to the CIC batch, however, no effect of HT on fatigue life of Inconel 713LC produced by VIC was observed. In contrast, the heat treated Inconel 713LC demonstrates slightly higher fatigue life in Coffin-Manson representation. The microstructure of both superalloys was studied by means of scanning electron microscopy (SEM). The microstructure of superalloy is characterized by dendritic grains with casting defects. It comprises the $\mathrm{y}$ matrix, cubic $\mathrm{Y}^{\prime}$ precipitates, eutectics and carbides. The effect of the VIC and HT on fatigue performance and microstructure of Inconel 713LC is discussed.
\end{abstract}

Keywords: Inconel 713LC, vibratory investment casting, hot isostatic pressing, high temperature low cycle fatigue, stress-strain response

\section{INTRODUCTION}

Nickel-based superalloy Inconel 713LC is an extensively used cast material for a diverse scale of high temperature components mainly due to its very favourable cost and outstanding fatigue and creep performance $[1,2]$. It is produced by a conventional investment casting method and as such Inconel $713 \mathrm{LC}$ contains casting defects that can adversely affect lifetime [3]. Hot isostatic pressing (HIP) technique provides an effective tool to heal casting defects [4,5], though, it can negatively affect the morphology of the $L 1_{2}$ ordered $\gamma^{\prime}$ precipitates and to restore the microstructure additional heat treatment (HT) is crucial but making production more expensive. To reduce the costs and provide material with diminished size and amount of casting defects a modification of the conventional investment casting $(\mathrm{CIC})$ could be done via including vibrations during solidification.

The present work is focused on the study of high temperature low cycle fatigue behaviour of Inconel 713LC produced by the vibratory investment casting (VIC) in as-cast conditions and in the condition after heat treatment (HT) consisting of hot isostatic pressing (HIP) followed by precipitation hardening. A comparison of data obtained from low cycle fatigue tests of Inconel 713LC produced by the VIC and of Inconel 713LC produced by the CIC obtained previously [6] is provided.

\section{EXPERIMENT}

A low carbon (LC) version of Inconel 713 was supplied by PBS, Velká Bíteš, a.s. in the form of button-end rod samples made by the CIC and VIC with a gauge length and diameter of $14 \mathrm{~mm}$ and $8 \mathrm{~mm}$, respectively. 
Selected samples produced by the VIC were heat treated. The HT process consists of HIP $\left(1200^{\circ} \mathrm{C} / 4 \mathrm{~h} /\right.$ $100 \mathrm{MPa})$ followed by precipitation hardening $\left(750^{\circ} \mathrm{C} / 4 \mathrm{~h}\right)$. The average grain size of the VIC batch and the $\mathrm{CIC}$ batch found using linear intercept method was $240 \mu \mathrm{m} \pm 47 \mu \mathrm{m}$ and $2.3 \mathrm{~mm} \pm 0.4$, respectively. The chemical composition of Inconel 713LC in wt\% is as follows: Ni-11.72Cr $-4.19 \mathrm{Mo}-0.05 \mathrm{C}-5.97 \mathrm{Al}-0.69 \mathrm{Ti}$ $1.95 \mathrm{Nb}-0.03 \mathrm{Ta}-0.1 \mathrm{Zr}-0.007 \mathrm{~B}$. The superalloy is typical of a dendritic structure with shrinkage pores (Figure 1). The microstructure consists of $y$ matrix, $Y^{\prime}$ strengthening phase, eutectics and carbides in a form of Chinese script. Cylindrical specimens with diameter and gauge length of 6 and $15 \mathrm{~mm}$, respectively, were applied to perform high temperature low cycle fatigue tests. Fatigue tests were conducted in a fully reversed push-pull cycle $(R \varepsilon=-1)$ under strain control mode with constant strain rate $2 \times 10^{-3} \mathrm{~s}^{-1}$ at $800{ }^{\circ} \mathrm{C}$ in air. Details of high temperature low cycle fatigue testing and tests evaluation could be found elsewhere [7]. Microstructural investigations were accomplished by means of the scanning electron microscope (SEM - TESCAN Lyra3 XMU) equipped with the energy dispersive X-ray (EDX) spectroscopy analyser.

\section{RESULTS AND DISCUSSION}

The initial microstructure of Inconel 713LC for all material conditions is shown in Figure 1(a-c) using backscatter electron imaging in channelling contrast. Vibrations support the nucleation of new grains during the solidification and thus effectively reduce the grain size. An introduction of vibrations in a casting process contributed to a reduction not only of the average grain size (compare Figure 1a and Figure 1b) but also the size of casting defects. The maximum size of shrinkage pores was $300 \mu \mathrm{m}$ in diameter in case of the CIC batch and $90 \mu \mathrm{m}$ for the VIC batches. Inlets in the right upper corner of Figures 1 (a-c) show the SEM image of $Y^{\prime}$ precipitates shape and it can be noticed that application of the HT into the production chain implies a tendency of $\mathrm{Y}^{\prime}$ precipitates to form an array of cubes (Figure 1c). The mechanism of $\mathrm{Y}^{\prime}$ precipitates coarsening is generally controlled by the lattice misfit between the $y$ matrix and $\mathrm{Y}^{\prime}$ strengthening precipitates producing the elastic strain energy and interfacial energy in the material, allowing higher mobility of interface due to the higher density of interfacial dislocations [8-10]. This phenomenon in a conjunction with various heat treatment conditions has been intensively studied by Ricks [11] in a wide range of nickel-based superalloys and it was found that the coherency stresses related to the lattice misfit influence also the morphology of the $\mathrm{Y}^{\prime}$ precipitates, which is in a good agreement with observed morphology of $\mathrm{Y}^{\prime}$ precipitates of the HTed Inconel 713LC. Besides, the anisotropic relaxation of the coherency stresses induced by the motion of dislocations during fatigue or creep loading can bring about another morphological change of $\mathrm{Y}^{\prime}$ precipitates. Figure 1d shows incipient "rafting" of $\mathrm{Y}^{\prime}$ precipitates of a $\mathrm{CIC}$ sample fatigued at $800{ }^{\circ} \mathrm{C}$ with a total strain amplitude of $0.45 \%$ [12-14]. Such a significant change in the shape of $\mathrm{Y}^{\prime}$ precipitates was found only in the CIC batch (compare with Figure 1e and inlet in Figure 1f) and, moreover, only in samples fatigued with the total strain amplitudes higher than $0.44 \%$. Cyclic straining with lower amplitudes does not affect the microstructure at all. This indicates the dependency of the rafting on the applied macroscopical stress as it was reported by Yu et al [15]. However, in the VIC batch, there is a tendency of $\mathrm{Y}^{\prime}$ precipitates to become more or less rounded (Figure 1e). The $\mathrm{Y}^{\prime}$ precipitates of the $\mathrm{VIC}+\mathrm{HT}$ batch seems to be even more resistible to rafting (inlet in Figure 1f) than of the VIC or CIC batch. With a decrease in the grain size, the process of fatigue crack initiation at grain boundaries and subsequent propagation of fatigue cracks along grain boundaries (Figure 1f) begin to play more critical role [16], mainly due to a higher incidence of impurities at grain boundaries.

Figure 2 characterizes the stress response of Inconel 713LC during cyclic straining at $800{ }^{\circ} \mathrm{C}$ in the representation of the stress amplitude versus the number of elapsed cycles. The cyclic hardening/softening curves were obtained for various total strain amplitudes for all material batches. Regardless of the material batch, the character of the hardening/softening curves of Inconel 713LC depends on the strain amplitude. The high amplitude domain is characterized by fatigue hardening, while saturated stress response is found in the medium and low amplitude domain. 

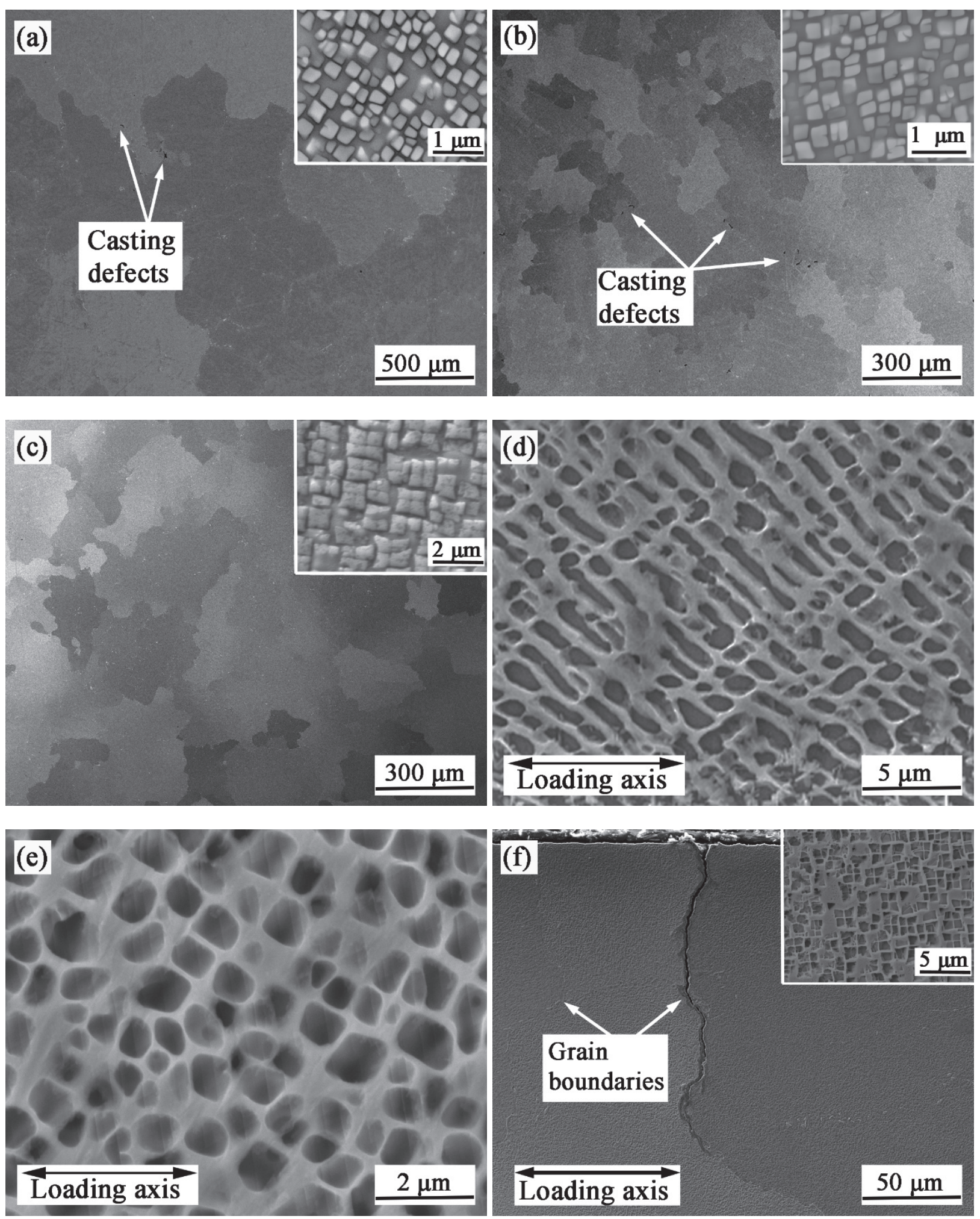

Figure 1 Microstructure of Inconel 713LC showing dendritic grains and morphology of $\mathrm{Y}^{\prime}$ precipitates produces via: (a) CIC conventional investment casting, (b) VIC vibratory investment casting, (c) VIC + HT vibratory investment casting with subsequent heat treatment, (d) precipitates morphology after fatigue (CIC sample), (e) precipitates morphology after fatigue (VIC + HT sample), (f) fatigue crack initiation and propagation along grain boundary (VIC sample) 

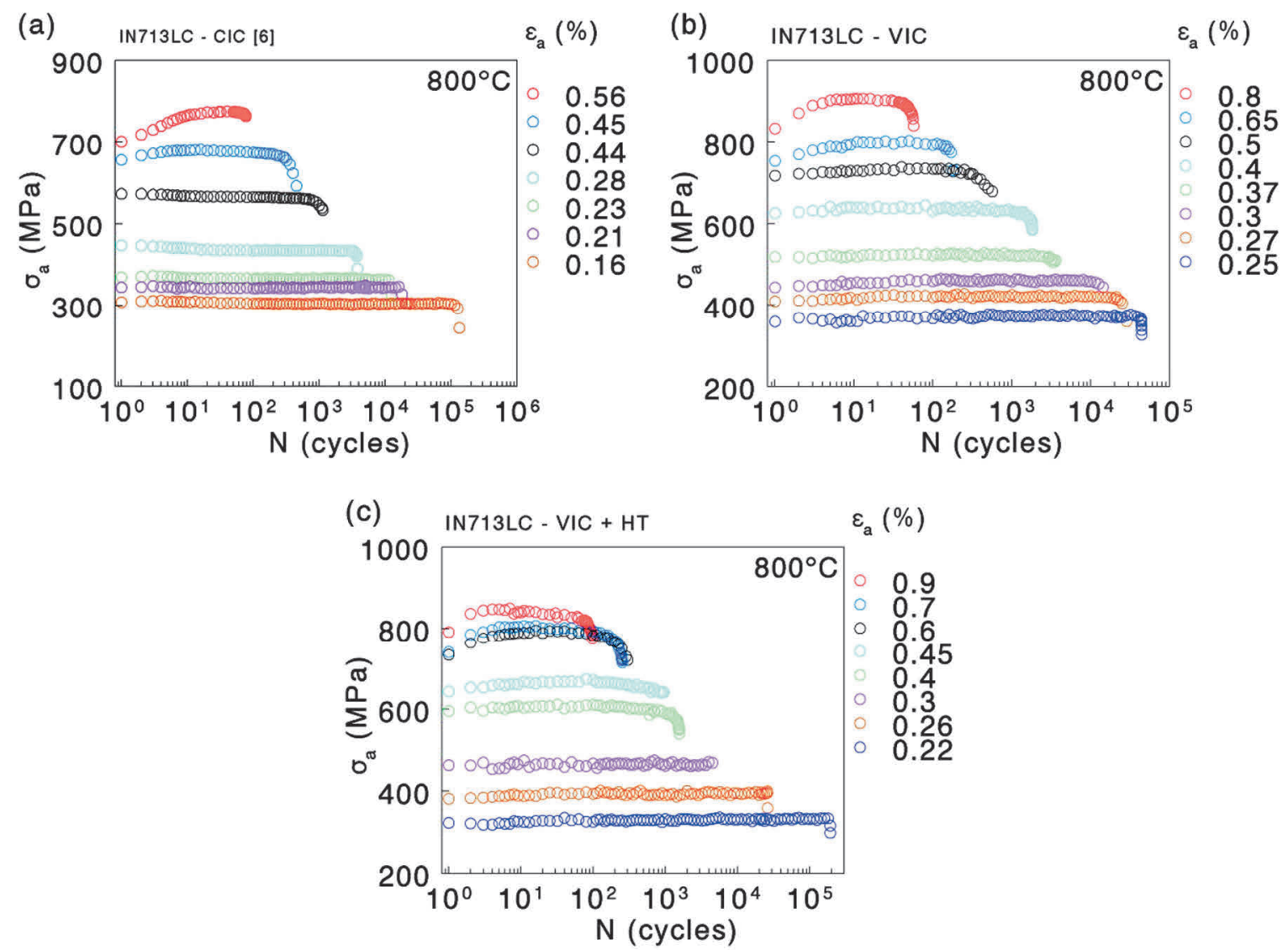

Figure 2 Cyclic hardening/softening curves of Inconel 713LC: (a) CIC, (b) VIC, (c) VIC + HT

Fatigue life curves in the representation of the stress amplitude $\sigma_{a}$ versus the number of cycles to fracture $\mathrm{N}_{f}$ are plotted in Figure 3a. The Basquin law expressed in the form:

$\log 2 N_{f}=\left(\frac{1}{b}\right) \log \sigma_{a}-\left(\frac{1}{b}\right) \log \sigma_{f}^{\prime}$

fits the experimental data obtained in low cycle fatigue tests. The fatigue strength coefficient $\sigma_{f}^{\prime}$ and the fatigue strength exponent $b$ were evaluated by regression analysis using least squares fitting and their values are listed in Table 1. It can be seen from Figure $3 a$ that the Basquin curves for the VIC and VIC + HT batches of Inconel 713LC are for the same fatigue life shifted of approximately $100 \mathrm{MPa}$ to higher stress amplitudes in comparison with the CIC Inconel 713LC. The shift to higher fatigue lifetime of the VIC and VIC + HT batches can be attributed to the grain size effect [17]. Figure 3a shows that the fatigue life in the Basquin representation is almost the same for the VIC and VIC + HT batch in the whole range of the stress amplitudes.

The plastic strain amplitude $\varepsilon_{a p}$ vs. $\mathrm{N}_{\mathrm{f}}$ is plotted in a bilogarithmic representation in Figure $\mathbf{3 b}$. The values of $\varepsilon_{a p}$ were established as the half width of the hysteresis loop at half-life. Experimental data were approximated by the Coffin-Manson law:

$\log 2 \mathrm{~N}_{\mathrm{f}}=\left(\frac{1}{c}\right) \log \varepsilon_{\mathrm{ap}}-\left(\frac{1}{c}\right) \log \varepsilon_{\mathrm{f}}^{\prime}$

where $\varepsilon_{\mathrm{f}}^{\prime}$ is the fatigue ductility coefficient and $c$ is the fatigue ductility exponent. The parameters were evaluated by regression analysis and are listed in Table 1. Data presented in Figure $\mathbf{3 b}$ show a positive impact of the VIC on fatigue life in the whole range of tested amplitudes. An additional improvement achieved by the introduction of the HT can be found in the high amplitude domain of the Coffin-Manson diagram. This behaviour 
can arise from a higher stability of arrays of $\mathrm{Y}^{\prime}$ cubes in the VIC batch after HT in comparison with individual $\mathrm{Y}^{\prime}$ cubes in the VIC batch (see again Figure 1), where the cyclic straining at $800^{\circ} \mathrm{C}$ in high amplitude domain resulted in a tendency of $\mathrm{Y}^{\prime}$ precipitates to begin to round (VIC sample - Figure 1e).

Table 1 The parameters of Basquin and Coffin-Manson fatigue life curves of Inconel 713LC

\begin{tabular}{|c|c|c|c|c|}
\hline Material batch & $\boldsymbol{\sigma}_{f}^{\prime}(\mathrm{MPa})$ & $\boldsymbol{b}$ & $\boldsymbol{\varepsilon}_{\mathrm{f}}^{\prime}(-)$ & $\boldsymbol{c}$ \\
\hline CIC & 2080 & -0.16 & 0.098 & -0.81 \\
\hline VIC & 1790 & -0.14 & 0.465 & -0.91 \\
\hline VIC + HT [6] & 1740 & -0.15 & 0.039 & 0.78 \\
\hline
\end{tabular}

(a)

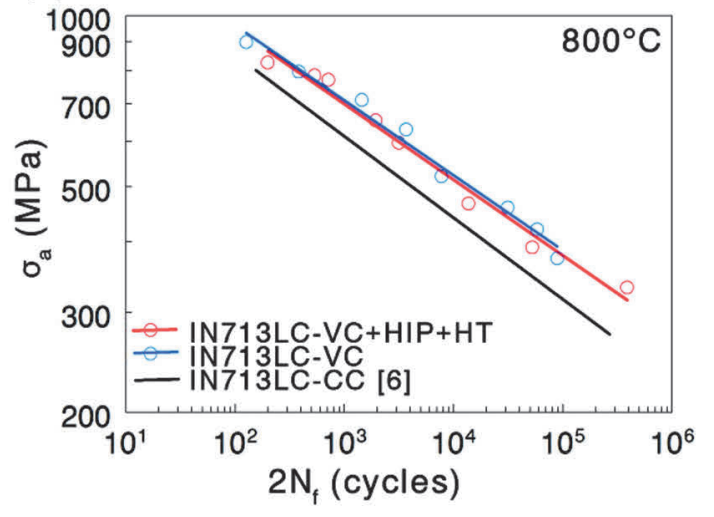

(b)

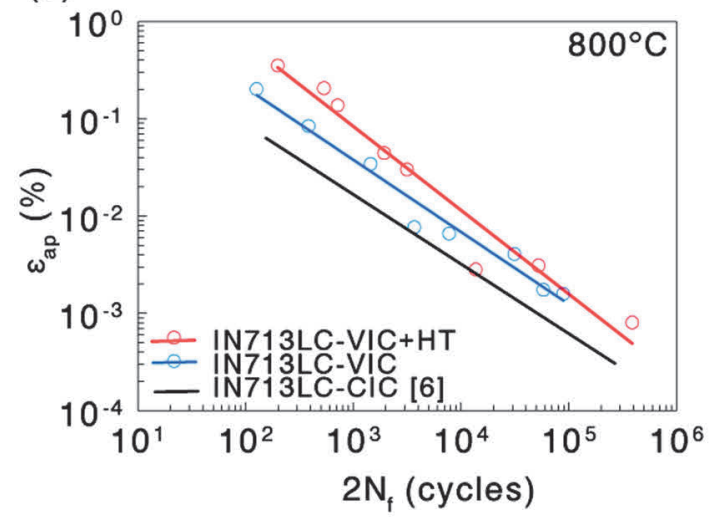

Figure 3 Fatigue life curves: (a) Basquin representation, (b) Coffin-Manson representation

\section{CONCLUSIONS}

The following conclusions can be drawn from the study of high temperature low cycle fatigue behaviour of Inconel 713LC produced by conventional investment casting and vibratory investment casting.

a) The average grain size and maximal size of casting defects of material prepared via VIC are considerably reduced in comparison with material produced by $\mathrm{CIC}$.

b) The microstructure of $\mathrm{Y}^{\prime}$ precipitates of both studied materials in as-cast conditions is identical. Heat treatment resulted in the formation of the array of cubes. Low cycle fatigue tests at $800{ }^{\circ} \mathrm{C}$ does not further affect the morphology of $\mathrm{Y}^{\prime}$ precipitates.

c) Low cycle fatigue tests conducted on Inconel 713LC clearly show improvement in fatigue life of material produced via VIC in comparison to CIC material both in the Basquin and Coffin-Manson representation.

d) Heat treatment of vibratory investment casting superalloy resulted in a small increase of fatigue life in the Coffin-Manson representation.

\section{ACKNOWLEDGEMENTS}

The present research was financially supported by the grant No. CZ.01.1.02/0.0/0.0/15_019/0002421 of the Ministry of Industry and Trade.

\section{REFERENCES}

[1] AZADI, M. and AZADI M. Evaluation of high-temperature creep behavior in Inconel-713C nickel-based superalloy considering effects of stress levels. Materials Science and Engineering: A. 2017. vol. 689, pp. 298-305. 
[2] GÁlVEZ, F., GARCIA, N., CENDÓN, D., ENFEDAQUE, A. and SÁNCHEZ-GÁLVEZ, V. Mechanical behaviour of Inconel 713LC at different strain rates and high temperatures. In DYMAT 2009: 9th International Conference on the Mechanical and Physical Behaviour of Materials under Dynamic Loading. 2009. pp. 861-866.

[3] KUNZ, L., LUKÁŠ, P., KONEČNÁ, R. and FINTOVÁ, S. Casting defects and high temperature fatigue life of IN 713LC superalloy. International Journal of Fatigue. 2012. vol. 41, pp. 47-51.

[4] BOR, H.Y., HSU, C. and WEI, C. N. Influence of hot isostatic pressing on the fracture transitions in the fine grain MAR-M247 superalloys. Materials Chemistry and Physics. 2004. vol. 84, pp. 284-290. doi:10.1016/j.matchemphys.2003.08.014.

[5] ŠULÁK, I., OBRTLÍK, K. and ČELKO, L. High-temperature low-cycle fatigue behaviour of HIP treated and untreated superalloy MAR-M247. Kovove Materialy. 2016. vol. 54, pp. 471-481.

[6] OBRTLÍK, K., POSPIŠILOVÁ, S., JULIŠ, M., PODRÁBSKÝ, T. and POLÁK, J. Fatigue behavior of coated and uncoated cast Inconel $713 \mathrm{LC}$ at $800{ }^{\circ} \mathrm{C}$. International Journal of Fatigue. 2012. vol. 41, pp. 101-106.

[7] OBRTLÍK, K., ČELKO, L., CHRÁSKA, T., ŠULÁK, I. and GEJDOŠ, P. Effect of alumina-silica-zirconia eutectic ceramic thermal barrier coating on the low cycle fatigue behaviour of cast polycrystalline nickel-based superalloy at $900{ }^{\circ} \mathrm{C}$. Surface and Coatings Technology. 2017. vol. 318, pp. 374-381.

[8] A.J. PORTER, A. J., ECOB, R. C. and RICKS, R. A. Coherency strain fields: magnitude and symmetry. Journal of Microscopy. 1983. vol. 129 pp. 327-336.

[9] ARDELL, A. J. The effects of elastic interactions on precipitate microstructural evolution in elastically inhomogeneous nickel-base alloys. Philosophical Magazine. 2014. vol. 94, pp. 2101-2130.

[10] REED, R.C. The Superalloys: Fundamentals and Applications. 1st ed. Cambridge, Cambridge University Press, 2008. p. 392.

[11] RICKS, R.A., PORTER, A. J. and ECOB, R. C. The growth of $\mathrm{Y}^{\prime}$ precipitates in nickel-base superalloys. Acta Metallurgica. 1983. vol. 31, pp. 43-53.

[12] CACCURI, V., CORMIER, J. and DESMORAT, R. Y'-Rafting mechanisms under complex mechanical stress state in Ni-based single crystalline superalloys. Materials \& Design. 2017. vol. 131, pp. 487-497.

[13] KRAFT, S., ALTENBERGER, I. and MUGHRABI, H. Directional $\gamma-\gamma^{\prime}$ coarsening in a monocrystalline nickel-based superalloy during low-cycle thermomechanical fatigue. Scripta Metallurgica et Materialia. 1995. vol. 32, pp. 411416.

[14] ICHITSUBO, T., KOUMOTO, D., HIRAO, M., TANAKA, K., OSAWA, M., YOKOKAWA, T. and HARADA, H. Rafting mechanism for Ni-base superalloy under external stress: elastic or elastic-plastic phenomena? Acta Materialia. 2003. vol. 51, pp. 4033-4044.

[15] YU, Z.Y., WANG, X.Z., YUE, Z.F. and WANG, X.M. Investigation on microstructure evolution and fracture morphology of single crystal nickel-base superalloys under creep-fatigue interaction loading. Materials Science and Engineering: A. 2017. vol. 697, pp. 126-131.

[16] ZHU, X., GONG, C., JIA, Y.-F., WANG, R., ZHANG, C., FU, Y., TU, S.-T. and ZHANG, X.-C. Influence of grain size on the small fatigue crack initiation and propagation behaviors of a nickel-based superalloy at $650{ }^{\circ} \mathrm{C}$. Journal of Materials Science \& Technology. 2019, in press.

[17] LIU, L.L., HU, D.Y., LI, D., HU, R.G., GU, Y.X. and WANG, R.Q. Effect of Grain Size on Low Cycle Fatigue Life in Compressor Disc Superalloy GH4169 at $600{ }^{\circ} \mathrm{C}$. Procedia Structural Integrity. 2017. vol. 7, pp. 174-181. 